INTERNATIONAL SyMPOSIUM ON

"Interactions between/Drugs used in Preparation for

Surgical Operations and Anaesthesia"

Recoaro Terme (Vicenza), Italy

September 1966

(Simultaneous translation will be performed in French, English, German, and Italian)

For further information contact:

Dr. Ruggiero Rizzi,

Ospedale Civile,

Vicenza, Italy.

\title{
CANADIAN OXYGEN PRIZE
}

Canadian Oxygen Limited have made available the sum of $\$ 1,000$ annually for the prize to be awarded by the Canadian Anaesthetists' Society for the best original work in Anaesthesia completed in Canada during the year preceding the award. The prize will be awarded at the time of the Annual Meeting of the Canadian Anaesthetists' Society in 1966. 'The following regulations apply:

\section{Qualification and Selection}

1. The prize will be awarded annually for the best original work published in the Canadian Anaesthetists' Society Journal prior to December 31st in each year, except that if in the opinion of the referees the studies published in that year do not warrant the making of the award, the prize will be deferred.

2. Studies may be of a basic or clinical nature, and must be carried out in a Canadian Hospital or University by a resident in training in Anaesthesia or a practising anaesthetist or a qualified anaesthetist engaged in basic or clinical research.

3. Four (4) referees will be appointed by the Executive of the Canadian Anaesthetists' Society from departments of Anaesthesia in Canadian Universities. Not more than one referee shall be chosen from any one University.

4. In the event that two (2) papers are judged by the referees to be of equal merit the award may be divided at the discretion of the referees. 